\title{
Finansal Gelişmenin Vergi Gelirleri Üzerine Etkisi: Geçiş Ekonomileri Örneği
}

\author{
Rabia Efeoğlua, b
}

Özet

Çalışmanın amacı, 22 geçiş ekonomisinde finansal gelişmenin vergi gelirleri üzerindeki etkisini 2004-2018 dönemini kapsayan veri setini kullanarak incelemektir. İki değişken arasındaki ilişkiyi analiz etmek için Westerlund panel eşbütünleşme testi ile Dumitrescu ve Hurlin panel nedensellik testi uygulanmıştır. Çalışmadan elde edilen bulgular, geçiş ekonomilerinde finansal gelişme ve vergi geliri arasında eşbütünleşme ilişkisinin varlı̆̆ını ortaya koymaktadır. Hem panelin bütünü hem de ülke bazında eşbütünleşme katsayıları Pesaran (2006) CCE yöntemi ile tahmin edilerek ülkelere özgü bulgular elde edilmiştir. Tahmin sonuçları geçiş ekonomilerinde finansal gelişmenin vergi geliri üzerinde pozitif ve anlamlı bir etkisinin olduğunu göstermektedir. Ancak ülke bazında finansal gelişmenin vergi gelirleri üzerinde pozitif etkisinin yanında negatif etkisinin de olabileceğini gösteren katsayılar olduğu tespit edilmiştir. Dumitrescu ve Hurlin panel nedensellik sonuçlarına göre de, finansal gelişme ve vergi gelirleri arasında çift yönlü bir nedensellik ilişkisi bulunmaktadır. Sonuç olarak, geçiş ekonomilerinde gelişen bir finansal sistemin vergi gelirlerini artırma eğiliminde olduğu söylenebilir.
Anahtar Kelimeler

Vergi Gelirleri

Finansal Gelişme

Panel Veri Analizi

Geçiş Ekonomileri

Makale Hakkında

Geliş Tarihi: 01.03.2021

Kabul Tarihi: 21.06.2021

Doi: $10.18026 /$ cbayarsos. 889044

\section{The Effect of Financial Development on Tax Revenues: Evidence from Transition Economies}

\section{Abstract}

The aim of the study is to examine the impact of financial development on tax revenues in 22 transition economies using the data set covering the period 2004-2018. Westerlund panel cointegration test and Dumitrescu and Hurlin panel causality test were applied to analyze the relationship between the two variables. The findings obtained from the study reveal the existence of a cointegration relationship between financial development and tax revenue in transition economies. Country-specific findings were obtained by estimating the cointegration coefficients of both the entire panel and the country with the Pesaran (2006) CCE method. Estimation results show that financial development has a positive and significant effect on tax revenues in transition economies. However, it has been determined that there are coefficients showing that financial development may have a negative effect as well as a positive effect on tax revenues. According to Dumitrescu and Hurlin panel causality results, there is a two-way causality relationship between financial development and tax revenues. As a result, it can be said that a developing financial system in transition economies tends to increase tax revenues.
Keywords

Tax Revenues

Financial Development

Panel Data Analysis

Transition Economies

About Article

Received: 01.03.2021

Accepted: 21.06.2021

Doi: $10.18026 /$ cbayarsos. 889044

a İletişim Yazarı: refeoglu@kastamonu.edu.tr

b Dr. Öğr. Üyesi, Kastamonu Üniversitesi İktisadi ve İdari Bilimler Fakültesi Finans ve Bankacıllk Bölümü, ORCID: 0000-0003-2515-1553. 


\section{Giriş}

Vergi gelirleri, devletlerin varlıklarını devam ettirebilmeleri için gerekli olan en önemli gelir kaynağıdır. Vergi gelirleri kamu harcamalarının finansmanında önemli bir araçtır ve sosyal, kültürel, ekonomik, siyasi olmak üzere birçok unsurdan etkilenmektedir. Söz konusu unsurlar detaylandırıldığında, vergi gelirlerinin belirleyicileri; ekonomik büyüme, kişi başına gelir, enflasyon oranı, gelir dağılımı, dışa açıklık, tarım, sanayi ve hizmet sektörlerinin milli gelir içerisindeki payları, kayıt dışı ekonominin büyüklüğü, dış yardımlar, nüfus, siyasal istikrar, yolsuzluk, rüşvet, küreselleşme, vergi rekabeti, bankacılık sektöründeki gelişmeler, vergi yapısı gibi birçok faktör sayılabilir. Tüm bu belirleyicilerin yanında finansal gelişmenin de vergi gelirlerinin belirleyicisi olduğuna dair çalışmalar söz konusudur.

Finansal gelişme; tasarruf ve yatırım yapılması, yapılan tasarruf ve yatırımların izlenmesi, tasarrufların toplanması, kaynakların toplanıp üretken alanlara veya yatırımlara aktarılmasını sağlama, mal ve hizmet değişimi ile risk çeşitlendirme gibi gelişmeleri kapsamaktadır (Svirydzenka, 2016). Dolayısıyla finansal gelişmenin vergi gelirlerini etkilemesi doğrudan veya dolaylı olarak gerçekleşebilmektedir. Şöyle ki; ekonomide finansal gelişmenin olması ekonomik büyümeyi artırabilir. Ekonomik büyüme ise, mal ve hizmetlere olan talep ile refah düzeyini artırarak yatırımların artmasını sağlayabilir, bunun sonucunda da vergi gelirleri yükselebilir. Öte taraftan, bir ülkenin finansal sistemi geliştikçe, finansal kurumlarının etkinliği, şeffaflığı ile finansal araçlarının çeşitliliği de artış göstereceğinden vergi mükelleflerinin finansal sistemi kullanma konusundaki motivasyonu artabilir. Bu durum vergi mükelleflerinin potansiyel kayıt dışı işlemlerini azaltabileceği gibi aynı zamanda devletin bu kimselerin vergilemeye esas gelir ve varlıkları hakkında daha fazla bilgi sahibi olmasını kolaylaştırabilir. Diğer taraftan finansal gelişme, vergilerin takip edilmesini ve tahsilini kolaylaştırmaktadır. Bu sebeple de finansal gelişme direkt olarak vergi gelirlerini arttırabilmektedir. Yani finansal gelişim sayesinde vergi mükellefleri hakkındaki daha net bilgilerin elde edilebilmesi ve eksik ya da hatalı beyanların tespit edilmesi; vergilerin takibini kolaylaştırarak vergi gelirlerinin artmasını sağlayabilir.

Son yıllarda güncel bir konu olarak incelenen finansal gelişmenin vergi gelirleri üzerine etkisi literatürü incelendiğinde bu alanda yapılan çalışmaların oldukça sınırlı olduğu görülmektedir. Sınırlı olan söz konusu çalışmalarda finansal gelişme göstergesi olarak ise genellikle bankacılık faaliyetleri, özel sektör kredileri, hisse senedi gibi göstergeler kullanılmış, ancak son yıllarda IMF tarafından geliştirilen finansal gelişmenin farklı boyutlarını yansıtan "finansal gelişme endeksi" göz ardı edilmiş, çok az sayıda çalışmada kullanılmıştır. Bu sebeple finansal gelişme endeksi kullanılarak finansal gelişmenin vergi gelirleri üzerindeki etkisi incelenmiştir. Ayrıca finansal gelişme ve vergi gelirleri ilişkisinin daha önce geçiş ekonomileri özelinde araştırıldığı çalışmalara rastlanılmaması ve bu çalışmada ele alınması çalışmanın diğer bir özelliğini yansıtmaktadır. Bu kapsamda geçiş ekonomilerinde finansal gelişmenin vergi gelirleri üzerindeki etkisi panel veri analiz yöntemi ile incelenerek literatüre söz konusu alanda bir katkı sağlanacağı düşünülmektedir. Çalışma beş bölümden oluşmakta olup, giriş bölümünü takiben literatür taraması, veri ve yöntem, ampirik bulgular ve sonuç sunulmaktadır.

\section{Vergi Gelirleri ve Finansal Gelişme}

Devletler ekonomik büyümelerini ve ekonomik kalkınmalarını sağlayabilmek için kamu gelirlerine ihtiyaç duymaktadırlar. Kamu gelirlerinin kaynağı çoğunlukla harcamalardan 
oluştuğundan devletlerin söz konusu kamu harcamalarını karşılamak için kullandığı en önemli gelir kaynağı vergi gelirleridir. Ekonomik, siyasi, sosyal ve kültürel birçok faktörden etkilenen vergi gelirleri bir yandan kamu harcamalarının finansmanını sağlarken diğer yandan da hükümetlerin finansal yapılarının gelişmesinde önemli bir yere sahiptir. Özellikle son yıllarda hükümetler finansal yapılarını artırabilmek için vergi gelirlerini önemli ölçüde artırma gayretindedirler. Bir ekonominin finansal yapısı, kişilerin vergiye ne ölçüde uyum sağladıklarıyla ilgilidir ve buna bağlı olarak değişiklik göstermektedir. Nitekim 1980'lerden itibaren serbest piyasa ekonomisine geçilmesinin birçok ekonomi politikasını olduğu gibi vergi politikasını da önemli derecede etkilediği, özel tasarruf ve yatırımların önem kazanarak özel sermaye birikiminin sağlandığı görülmektedir (Bahtiyar ve Odabaş, 2020). Diğer taraftan finansal gelişim; finansal piyasaların derinleşmesini, finansal piyasa araçlarının çeşitlilik göstermesini ve finansal piyasalarda faaliyette bulunan kurumların sayılarının artmasını sağlamaktadır (Koç, Şenol ve Karaca, 2016). Böylece finansal gelişme teknolojinin yayılması, sermaye birikimi ve kaynakların tahsisini kolaylaştırıp ekonomik büyümeyi sağlayarak vergi gelirini etkileyebilir ki bu etki pozitif yönlü bir etkidir.

Finansal gelişmenin vergi gelirleri üzerindeki etkisi doğrudan ve dolaylı olmak üzere üç şekilde gerçekleşmektedir. Birincisi, finansal gelişmenin ekonomik büyümeye yol açarak vergilendirilebilir ekonomik faaliyetlerin genişlemesi sonucu vergi gelirlerinin artması şeklindedir. Finansal gelişmenin ekonomik büyümeyi etkilemesi ise, arz öncüllü hipotez, talep takipli hipotez ve geri besleme hipotezi biçiminde olmaktadır. Arz öncüllü hipotezde, finansal gelişim gerekli fonları temin ederek teknolojik gelişme ve sermaye birikimini sağlayarak ekonomik büyümeyi etkilemektedir. Talep takipli hipotezde, ekonomik büyümenin finansal gelişmeyi sağlaması söz konusudur. Geri besleme hipotezinde ise finansal gelişme ekonomik büyümeyi sağlarken ekonomik büyüme de finansal gelişmeyi sağlamaktadır (Pata ve Ela, 2020). Ekonomik büyümedeki artışlar da vergilendirilebilir ekonomik faaliyetleri genişletmekte ve vergi gelirini arttırmaktadır (Terefe ve Teera, 2018). Íkincisi, ekonomik büyümenin refah düzeyini artırarak mal ve hizmetlere olan talebi arttırması ile yeni yatırımların gerçekleştirilmesi ve vergi gelirlerinin artmasıdır (Tzougas, 2013). Üçüncüsü, finansal gelişmenin vergilerin izlenmesi ve tahsilini kolaylaştırması sonucu vergi gelirlerinin artmasıdır. Vergi mükellefleri bazen eksik ya da hatalı beyan vererek gelirlerinin önemli bir kısmını belirtmek istemezler. Bunun önüne geçebilmek amacıyla kayıtdışı ekonomiyi azaltması yönünde finansal gelişimin sağlanmasına önem verilerek vergi gelirlerinin artması sağlanabilmektedir (Bittencourt, Gupta ve Stander, 2014).

Son yıllarda önemli bir araştırma konusu olan finansal gelişmenin vergi gelirleri üzerindeki etkisine dair sınırlı sayıda çalışma vardır. Çalışmalarda finansal gelişmenin vergi gelirleri üzerindeki etkisi Türkiye için, çeşitli ülkeler bazında ve değişik ülke gruplarında incelenmiştir. Türkiye için finansal gelişmenin vergi gelirleri üzerindeki etkisini ele alan çalışmalardan Akçay, Sağbaş ve Demirtaş (2016), Türkiye için 2006-2014 döneminde bankacılık ve banka dışı faaliyetler ile vergi gelirleri arasındaki ilişkiyi araştırmışlardır. Bankacılık ve banka dışı faaliyetlerin uzun dönemde vergi gelirlerinin Granger nedeni olduğu, kısa dönemde ise yalnızca bankacılık sektörünün vergi gelirlerinin Granger nedeni olduğu bulgusunu elde etmişlerdir. Bayar ve Karamelikli (2017), 2006-2016 dönemi için Türkiye'de finansal gelişme ve vergi gelirleri arasındaki ilişkiyi doğrusal olmayan eşbütünleşme analizi ile test etmişlerdir. Doğrusal olmayan durumlarda hem hisse senedi hem de bankacilık sektörünün gelişmişlik düzeyi toplam vergi gelirlerini olumlu etkilemektedir. Doğrusal olmayan durumlar göz ardı edildiğinde ise finansal gelişme göstergeleri ile vergi gelirleri 
arasında bir ilişki yoktur. Pata ve Ela yaptıkları çalışmada (2020) finansal gelişmenin vergi gelirleri üzerindeki etkisini Türkiye için 1965-2017 dönemi verileriyle incelemişlerdir. Çalışma sonucuna göre, finansal gelişmedeki artış vergi gelirlerini artırmaktadır. Finansal gelişme ve vergi gelirleri arasında çift yönlü bir nedensellik vardır.

Çeşitli ülkeler bazında finansal gelişmenin vergi gelirleri üzerindeki etkisini ele alan çalışmalardan Taha, Colombage, Maslyuk ve Nanthakumar (2013), 1997-2008 döneminde Malezya' da bankacılık ve banka dışı faaliyetler ile vergi gelirleri arasındaki ilişkiyi ARDL analizi ile incelemişlerdir. Finansal sistem ile vergi gelirleri arasında uzun dönemli bir ilişkinin olduğunun ve hisse senedinden vergi gelirlerine doğru tek yönlü bir nedenselliğin olduğu sonucuna varmışlardır. Akram tarafından yapılan çalışmada (2016), 1975-2014 döneminde Pakistan için finansal sistem ve vergi gelirleri arasındaki ilişki analiz edilmiştir. Piyasa kapitalizasyonunun ve banka şubelerinin sayısının vergi gelirleri üzerinde uzun vadede olumlu bir etkisi vardır. Özel sektöre verilen krediler ile vergi gelirleri arasında çift yönlü bir nedensellik varken, kamu sektörü kredisi ve vergi gelirleri arasında anlamlı bir ilişki yoktur. Loganathan, Ismail, Streimikiene, Hassan, Zavadskas ve Mardani (2017), 1970-2015 döneminde Malezya için finansal gelişmenin vergi gelirleri üzerindeki etkisini incelemişler, vergilendirmeden finansal gelişmeye doğru tek yönlü bir nedensellik ilişkisinin olduğu sonucunu elde etmişlerdir. Ebi (2018), Nijerya'da 1993-2017 dönemi için finansal gelişmenin vergi gelirleri üzerindeki etkisini incelemiştir. Çalışmada finansal gelişmenin vergi gelirlerini artırdığını ortaya koymuştur. Taha, Šliogerienè, Loganathan, Jokšienė, Shahbaz ve Mardani (2018), Malezya için 1970-2015 döneminde finansal gelişme ile vergi gelirleri arasındaki ilişkiyi araştırmışlardır. Finansal gelişme ve vergi gelirleri arasında ters U ilişkisi bulgusunu elde etmişlerdir. Loganathan, Ahmad, Subramaniam ve Taha (2020), Malezya'da 1970-2017 dönemi için finansal gelişmenin vergi gelirleri üzerindeki etkisini ARDL analizi ile incelemişler, finansal gelişmenin vergi gelirleri üzerinde olumsuz bir etkisi olduğunu ortaya koymuşlardır.

Değişik ülke gruplarında finansal gelişmenin vergi gelirleri üzerindeki etkisini ele alan çalışmalardan Ilievski (2012), 100'den fazla ülkede 1990-2008 dönemi için bankacılık sektörü, hisse senedi piyasası ve finansal serbestleşmenin vergi gelirleri üzerindeki etkisini panel veri analiz yöntemiyle incelemiştir. Çalışmada bankacilık sektörü ve hisse senedi piyasasının vergi gelirlerini artırdığını ortaya koymuştur. Gilbert ve Ilievski yaptıkları çalışmada (2016) finans sektörünün vergi gelirleri üzerindeki etkisini 126 ülke için 1990-2011 dönemi verileriyle panel veri analiz yöntemini kullanarak incelemişlerdir. Çalışma sonucuna göre, artan bankacılık faaliyetleri beklenen vergi gelirlerini artırmaktadır. Bayar, Şaşmaz ve Öztürk (2017), OECD ülkelerinde 2001-2016 dönemini ele alarak panel veri analiz yöntemi ile finansal gelişme ve vergi gelirleri arasındaki ilişkiyi araştırmışlardır. Bankacılık sektörü ve hisse senedi piyasasının gelişiminin vergi gelirleri üzerindeki etkisi ülkelerde farklılaşmaktadır. Bankacılık sektörü ve hisse senedi piyasasının gelişmişlik düzeyinden vergi gelirlerine doğru tek yönlü bir nedensellik vardır. Nnyanzi, , Bbale ve Sendi (2018), Doğu Afrika'da 1990-2014 döneminde finansal gelişme ile vergi gelirleri arasındaki ilişkiyi panel veri analizi ile incelemişlerdir. Finansal gelişmenin vergi gelirleri üzerinde pozitif bir etkisi olduğu sonucuna varmışlardır. Gnangnon tarafından yapılan çalışmada (2019), 104 ülke için 1980-2014 döneminde finansal gelişme ve vergi gelirleri arasındaki ilişki analiz edilmiştir. Çalışmanın sonuçlarına göre, finansal gelişme vergi gelirlerini olumlu etkilemektedir. Topuz (2021), 21 gelişmekte olan ülkede 1990-2017 dönemini ele alarak panel veri analiz yöntemi ile 
finansal gelişmenin vergi gelirleri üzerindeki etkisini araştırmıştır. Finansal gelişmenin vergi gelirlerini artırdığını tespit etmiştir.

\section{Literatür Taraması}

Literatür incelendiğinde vergi gelirlerini etkileyen birçok değişkenin olduğu, fakat bunlar arasında finansal gelişmenin vergi gelirleri üzerindeki etkisini inceleyen çalışmaların oldukça sınırlı olduğu görülmektedir. Ancak yapılan çalışmalarda genel kanı finansal gelişmenin vergi gelirleri üzerindeki etkisinin pozitif olduğu yönündedir. Çalışmalar genel olarak zaman serisi ve panel veri analizlerine dayanmaktadır. Finansal gelişme göstergesi olarak genellikle bankacılık faaliyetleri, özel sektör kredileri, hisse senedi gibi göstergeler kullanılmıştır.

Finansal gelişmenin vergi gelirleri üzerindeki etkisini araştıran çalışmalarda finansal gelişmenin vergi gelirlerini yoğun bir şekilde pozitif etkilediği (Ilievski, 2012; Taha ve diğerleri, 2013; Akçay ve diğerleri, 2016; Akram, 2016; Gilbert ve Ilievski, 2016; Bayar ve Karamelikli, 2017; Bayar ve diğerleri, 2017; Ebi, 2018; Nnyanzi ve diğerleri, 2018; Gnangnon, 2019; Pata ve Ela, 2020; Topuz, 2021); çok az sayıda negatif etkilediği (Loganathan ve diğerleri, 2017; Loganathan ve diğerleri, 2020) görülmektedir. Bununla birlikte çalışmalarda finansal gelişme ile vergi gelirleri arasındaki çift yönlü nedensellik ilişkisi (Akram, 2016; Pata ve Ela, 2020) ve tek yönlü nedensellik ilişkisi de (Taha ve diğerleri, 2013; Akçay ve diğerleri, 2016; Bayar ve diğerleri, 2017) tespit edilmiştir. Finansal gelişme ve vergi gelirleri arasında ters U ilişkisi bulan çalışmalar da (Taha ve diğerleri, 2018) vardır.

Çalışmalarda finansal gelişmenin vergi gelirleri üzerindeki etkisi Türkiye için, çeşitli ülkeler bazında ve değişik ülke gruplarında araştırılmıştır. Finansal gelişmenin vergi gelirleri üzerindeki etkisini Türkiye için araştıran çalışmalar (Akçay ve diğerleri, 2016; Bayar ve Karamelikli, 2017; Pata ve Ela, 2020); çeşitli ülkeler bazında araştıran çalışmalar (Taha ve diğerleri, 2013; Akram, 2016; Loganathan ve diğerleri, 2017; Ebi, 2018; Taha ve diğerleri, 2018; Loganathan ve diğerleri, 2020); değişik ülke gruplarında araştıran çalışmalar (Ilievski, 2012; Gilbert ve Ilievski, 2016; Bayar ve diğerleri, 2017; Nnyanzi ve diğerleri, 2018; Gnangnon, 2019; Topuz, 2021) şeklindedir.

\section{Veri Seti ve Ekonometrik Yöntem}

Çalışmada 22 geçiş ekonomisinde (Arnavutkluk, Ermenistan, Kazakistan, Moldova, Tacikistan, Ukrayna, Belarus, Bosna Hersek, Gürcistan, Sırbistan, Bulgaristan, Hirvatistan, Çek Cumhuriyeti, Estonya, Macaristan, Letonya, Litvanya, Polonya, Romanya, Slovakya, Slovenya, Rusya) 2004-2018 dönemi verileri kullanılarak finansal gelişmenin vergi gelirleri üzerindeki etkileri analiz edilmiştir. Finansal gelişmeyi temsil eden finansal gelişme endeksi IMF (International Monetary Fund), vergi gelirleri ICTD (International Centre for Tax and Developmet) veri tabanından elde edilmiştir. Finansal gelişme ve vergi gelirleri arasındaki ilişkinin belirlenmesi amacıyla panel birim kök sinaması, Westerlund (2007) panel eşbütünleşme testi, Pesaran (2006) CCE tahmin yöntemi ile Dumitrescu ve Hurlin panel nedensellik testleri uygulanmıştır. Çalışmada kullanılan değişkenlere ait bilgiler Tablo 1'de sunulmuştur. 
Tablo 1. Çalışmada Kullanılan Değişkenlere Ait Bilgiler

\begin{tabular}{llll}
\hline Değişken & Sembol & Açıklama & Kaynak \\
\hline Vergi geliri & TAX & Vergi gelirlerinin GSYH'ya oranı & ICTD \\
Finansal gelişme & FDI & Finansal gelişme endeksi & IMF \\
\hline
\end{tabular}

Finansal gelişmenin vergi gelirleri üzerindeki etkisinin geçiş ekonomileri özelinde araştırıldığı çalışmada, ilk önce değişkenlerde yatay kesit bağımlılığının varlığı test edilmelidir. Yatay kesit bağımlılı̆̆ının varlığına göre de hangi birim kök testinin kullanılması gerektiği belirlenmiş olacaktır. Yani durağanlık sınaması yapılmadan önce birinci nesil veya ikinci nesil birim kök testlerinden hangisinin kullanılacağına karar verilmelidir. Genel olarak yatay kesit bağımlılık testlerinde üç test kullanılmaktadır. Bunlar; Breusch-Pagan (1980) LM testi, Pesaran (2004) LMcD testi ve Pesaran, Ullah ve Yamagata (2008) LMadj testleridir. Breusch-Pagan LM testi, T'nin büyük N'nin küçük olduğu $(T>N)$ durumda uygulanan bir yatay kesit bağımlılık testidir (Breusch ve Pagan, 1980). Pesaran LMcD testi, N'nin büyük T'nin küçük olduğu (N>T) durumda yatay kesit bağımlılığının olup olmadığını araştıran bir tahmincidir (Pesaran, 2004). Pesaran ve diğerleri LMadj testi ise, $N$ ve T'nin büyük olduğu $(\mathrm{N}>\mathrm{T}$ veya $\mathrm{T}>\mathrm{N}$ ) durumda uygulanan bir testtir (Pesaran, Ullah ve Yamagata, 2008; Yerdelen Tatoğlu, 2017). Analizinde 22 ülke (N) ve 15 yıl (T) olan çalışmada $N>T$ olduğundan yatay kesit bağımlılığını belirlemek için Pesaran (2004) LMCD testi ile Pesaran ve diğgerleri (2008) LMadj. testi kullanılmıştır. LMCD testi ve LMadj testi sırasıyla aşağıdaki gibi formüle edilmiştir (Pesaran, 2004; Pesaran ve diğerleri, 2008).

$$
\begin{gathered}
L M_{C D}=\sqrt{\frac{2 T}{N(N-1)}}\left(\sum_{i=1}^{N-1} \sum_{j=i+1}^{N} \rho_{i j}\right) \\
L M_{a d j}=\sqrt{\frac{2}{N(N-1)}} \sum_{i=1}^{N-1} \sum_{j=i+1}^{N} \frac{(T-K) \rho_{i j}^{2}-\mu_{T_{i j}}}{\vartheta_{T_{i j}}}
\end{gathered}
$$

Pesaran (2004) LMcD ve Pesaran ve diğerleri (2008) LMadj testlerinin $\mathrm{H}_{0}$ hipotezi "yatay kesit bağımlılığ1 yoktur", H1 hipotezi "yatay kesit bağımlılığı vardır" şeklindedir. Pesaran (2004) LMCD ve Pesaran ve diğerleri (2008) LMadj testleri sonucunda olasılık değeri 0,05 'ten küçük elde edilirse $\mathrm{H}_{0}$ hipotezini ifade eden "yatay kesit bağımlılı̆̆ yoktur" hipotezi \%5 anlamlılık düzeyinde reddedilmekte ve bu durumda değişkenler arasında yatay kesit bağımlılı̆̆ının olduğu sonucuna ulaşılmaktadır (Pesaran, 2004, 2008).

Diğer taraftan modelin homojen bir yapıda olup olmadığına karar vermek için Pesaran ve Yamagata (2008) homojenlik testi yapılmıştır. Eğim katsayılarının homojenliğini belirleyebilmek amacıyla ilk çalışma Swamy (1971) tarafından yapılmış, daha sonra Pesaran ve Yamagata (2008) tarafından geliştirilmiştir (Pesaran ve Yamagata, 2008).

$$
Y_{i t}=\alpha+\beta_{i} X_{i}+\varepsilon_{i t}
$$

3 nolu eşitlikte $\beta \_$i eğim katsayısının yatay kesitler arasında farklı olup olmadığ sınanmaktadır. Testin $\mathrm{H}_{0}$ hipotezi "eğim katsayıları homojendir", $\mathrm{H}_{1}$ hipotezi "eğim katsayıları homojen değildir" şeklindedir. Pesaran ve Yamagata (2008) hipotezleri sınamak için iki test geliştirmişlerdir (Pesaran ve Yamagata, 2008).

$$
\Delta=\sqrt{N}\left(\frac{N^{-1} S-k}{2 k}\right) \sim \chi_{k}^{2}
$$




$$
\Delta_{a d j}=\sqrt{N}\left(\frac{N^{-1} S-k}{v(T, k)}\right) \sim N(0,1)
$$

4 ve 5 nolu denklemlerde N, yatay kesit birimlerinin sayısını; S, Swamy test istatistiğini; k, açılayıcı değişken sayısını; v(T,k), standart hatayı ifade etmektedir.

Çalışmada paneli oluşturan değişkenlerde durağanlık sınaması yapmak amacıyla Pesaran (2007) CADF testi yapılmıştır. CADF testi, ikinci nesil birim kök testlerindendir ve yatay kesit bağımlılığı durumunda kullanılır. CADF testinde, Genişletilmiş Dickey-Fuller regresyonundan elde edilen gecikmeli yatay kesit ortalamaları dikkate alınır. ADF regresyonunun birinci farkı alınarak, yatay kesit bağımlılığı ortadan kaldırılır. Dolayısıyla CADF regresyon eşitliği (Pesaran, 2007);

$$
\Delta Y_{i, t}=\alpha_{i}+\rho_{i}^{*} Y_{i t-1}+d_{0} \bar{Y}_{t-1} d_{1} \bar{Y}_{t}+\varepsilon_{i t}
$$

CADF regresyonu tahmin edildikten sonra CIPS istatistiği gecikmeli değişkenlerin $\mathrm{t}$ istatistiklerinin ortalamalarından (CADFi) hesaplanır. CIPS istatistiği (Pesaran, 2007);

$$
C I P S=C A D F_{\mathrm{I}}=\frac{\sum_{i=1}^{N} C A D F_{i}}{N}
$$

CADF testinin hipotezleri ise "Ho: birim kök var" ve “ $\mathrm{H}_{1}$ : birim kök yok" biçimdedir. Olasılık değeri 0,05 'ten küçük ise $\mathrm{H}_{0}$ hipotezi reddedilmekte serinin durağan olduğuna karar verilmektedir.

Değişkenlerin durağanlık seviyesi belirlendikten sonraki aşamada değişkenler arasında uzun dönemli bir ilişkinin olup olmadığını tespit etmek amacıyla ikinci kuşak panel eşbütünleşme testlerinden Westerlund (2007) panel eşbütünleşme testi uygulanmıştır. Westerlund (2007), panel veri analizlerinde eşbütünleşmenin varlığını sınamak amacıyla hata düzeltme modeli temelli 4 adet panel eşbütünleşme testi önermiştir. Ho hipotezi "eşbütünleşme yoktur" şeklinde olan testin modeli (Westerlund, 2007);

$$
\Delta Y_{i t}=\delta_{i}^{\prime} d_{t}+\alpha_{i} Y_{i t-1}+\lambda_{i}^{\prime} X_{i t-1}+\sum_{j=1}^{p_{i}} \varphi_{i j} \Delta Y_{i t-j}+\sum_{j=0}^{p_{i}} \gamma_{i j} \Delta X_{i t-j}+e_{i t}
$$

4 adet panel eşbütünleşme testi ise $\mathrm{Gt}, \mathrm{Ga}, \mathrm{Pt}, \mathrm{Pa}$ testleridir. Gt, Ga grup ortalama istatistiklerini göstermekte olup panelin heterojen olması durumunda daha fazla güvenilen testler iken; $\mathrm{Pt}, \mathrm{Pa}$ panel istatistiklerini göstermekte olup panelin homojen olması durumunda daha fazla güvenilen testlerdir (Westerlund, 2007; Yerdelen Tatoğlu, 2017). Değişkenler arasında eşbütünleşme ilişkisi olduğu tespit edildikten sonra uzun dönem eşbütünleşme katsayıları CCE (Common Correlated Effect-Ortak Korelasyonlu Etkiler) yöntemi ile tahmin edilmiştir (Pesaran, 2006).

Eşbütünleşme ilişkisinin varlığı belirlenip, eşbütünleşme katsayı tahmini sonrasında değişkenler arasındaki ilişkinin yönünü belirlemek amacıyla heterojen paneller için kullanılan Dumitrescu ve Hurlin nedensellik testi yapılmıştır. Test aşağıdaki gibi modellenmektedir (Dumitrescu ve Hurlin, 2012).

$$
Y_{i t}=\alpha_{i}+\sum_{k=1}^{K} \gamma_{i}^{(k)} Y_{i t-k}+\sum_{k=1}^{K} \beta_{i}^{(k)} X_{i t-k}+\varepsilon_{i t}
$$

Dumitrescu ve Hurlin testinin hipotezleri “Ho: tüm birimler için y değişkeni, $x$ değişkeninin nedenseli değildir" ve "H1: bazı birimler için y değişkeni, x değişkeninin nedenselidir" biçimindedir (Dumitrescu ve Hurlin, 2012). Bu yöntemde heterojenlik dikkate alınmakla birlikte yatay kesit bağımlılığı da göz önünde bulundurulmaktadır. 


\section{Ampirik Bulgular}

22 geçiş ekonomisinde finansal gelişmenin vergi gelirleri üzerindeki etkisinin ele alındığ çalışmada panel eşbütünleşme ve panel nedensellik testleri ile değişkenler arasındaki ilişki belirlenmektedir. Ancak öncesinde değişkenlere ilişkin tanımlayıcı istatistikler ve korelasyon analizi sunulmaktadır.

Tablo 2. Tanımlayıcı İstatistikler

\begin{tabular}{lll}
\hline & TAX & FDI \\
\hline Ortalama & 30.302 & 0.304 \\
Standart Hata & 6.037 & 0.126 \\
Minimum & 15.167 & 0.060 \\
Maksimum & 47.107 & 0.578 \\
\hline
\end{tabular}

22 geçiş ekonomisine ait tanımlayıcı istatistikleri gösteren Tablo 2'ye göre, 2004 - 2018 döneminde en yüksek vergi geliri 2008 yılında 47.107 ile Belarus'da iken, en düşük vergi geliri 2004 yılında 15.167 ile Tacikistan'dadır. En yüksek finansal gelişme endeksi 2009 yılında 0.58 ile Macaristan'da iken, en düşük finansal gelişme endeksi 2004, 2005, 2006 yıllarında 0.06 ile Tacikistan'dadır.

Tablo 3. Korelasyon Katsayıs1

\begin{tabular}{lll}
\hline & TAX & FDI \\
\hline TAX & 1.0000 & \\
FDI & 0.4883 & 1.0000 \\
\hline
\end{tabular}

Tablo 3'e göre korelasyon katsayıları değerlendirildiğinde, vergi gelirleri ve finansal gelişme arasında pozitif ve \%48'lik bir korelasyon bulunmaktadır. Ayrıca finansal gelişme ile vergi gelirleri arasındaki ilişki istatistiki olarak anlamlıdır.

Çalışmada panel eşbütünleşme ve panel nedensellik analizleri yapılmadan önce hangi eşbütünleşme ve nedensellik testlerinin kullanılacağına karar vermek için Pesaran ve Yamagata (2008) delta homojenlik testi ve yatay kesit bağımlılık testi yapılmıştır. Delta testi ile eğim katsayılarının homojenliği belirlenmeye çalışılmıştır. Delta test sonuçları Tablo 4'deki gibidir.

Tablo 4. Delta Testi

\begin{tabular}{lll}
\hline Test & Test İstatistiği & Olasılık Değeri \\
\hline$\Delta$ & 4.041 & 0.0000 \\
\hline$\Delta_{\text {adj }}$ & 4.518 & 0.0000 \\
\hline
\end{tabular}

Tablo 4 incelendiğinde, sıfır hipotezinin reddedildiği, dolayısıyla modelde eğim katsayılarının heterojen olduğu sonucuna varılmıştır. 
Eğim katsayılarının heterojen olduğu tespit edildikten sonra değişkenlerde yatay kesit bağımlılığının olup olmadığı incelenmiştir. Çalışmada veri setinde $N>T$ olduğu için yatay kesit bağımlılığının tespitinde Pesaran (2004) LMCD testi ile Pesaran ve diğerleri (2008) LMadj testleri kullanılmıştır.

Tablo 5. Yatay Kesit Bağımlılık Testi

\begin{tabular}{lll}
\hline & İstatistik & Olasılık \\
\hline LMCD & 4.15 & 0.0000 \\
LMadj. & 27.55 & 0.0000 \\
\hline
\end{tabular}

LMCD ve LMadj testlerine göre, olasılık değerleri \%1'den küçük olduğu için $H_{0}$ hipotezi reddedilerek modelde yatay kesit bağımlılı̆̆ının olduğuna karar verilmiştir.

Yatay kesit bağımlılı̆̆ı ve homojenlik test sonuçları, ikinci nesil birim kök testlerinin kullanılması gerektiğini göstermiştir. Bu nedenle çalışmada ikinci nesil birim kök testlerinden CADF sınaması yapılarak bulgular Tablo 6' da verilmiştir.

Tablo 6. CADF Panel Birim Kök Testi Sonuçları

\begin{tabular}{lllllll}
\hline & t-bar & cv10 & cv5 & cv1 & Z[t-bar] & Olasılık \\
\hline TAX & -1.798 & -2.070 & -2.170 & -2.340 & -0.334 & 0.369 \\
DTAX & -2.610 & -2.070 & -2.170 & -2.340 & -3.793 & $0.000^{* * *}$ \\
FDI & -1.687 & -2.070 & -2.170 & -2.340 & 0.141 & 0.556 \\
DFDI & -2.940 & -2.070 & -2.170 & -2.340 & -5.201 & $0.000^{* * *}$ \\
\hline
\end{tabular}

Not: Pesaran CADF testi gecikme sayısı 1 olarak alınmıştır. “ $\mathrm{D}$ “ işareti değişkenlerin birinci farkının alındığını; ${ }^{* * * * *, *}$ işaretleri \% 1,\% 5 ve \% 10 düzeylerinde istatistiki anlamlılığı göstermektedir.

CADF birim kök testi sonuçlarına göre, TAX ve FDI değişkenleri seviye değerlerinde durağan değildir. Değişkenlerin birinci farkları alındığında istatistiki bakımdan \%1 anlamlılık düzeyinde durağanlaşmışlardır. Değişkenler I(1) seviyesinde durağan olduklarından Westerlund (2007) panel eşbütünleşme testi ile eşbütünleşme ilişkinin varlığ sinanmıştır.

Westerlund (2007) panel eşbütünleşme testinde, panelin heterojen olması durumunda Gt ve Ga istatistiklerinin dikkate alınması gerekir. Bunun yanı sıra serilerin yatay kesit bağımlılığı durumunda bootstrap olasılık değerlerinin kullanılması önerilmektedir. Çalışmada panelin heterojen olması ve serilerde yatay kesit bağımlılığı olmasından dolayı Gt ve Ga istatistiklerinin bootstrap olasılık değerleri dikkate alınmıştır.

Tablo 7. Westerlund Panel Eşbütünleşme Test Sonuçları

\begin{tabular}{lllll}
\hline Test & İstatistik & Z-İstatistik & Olasılık & Bootstrap-Olasılık \\
\hline $\mathrm{Gt}$ & -3.066 & -6.717 & 0.000 & 0.040 \\
$\mathrm{Ga}$ & -12.038 & -4.186 & 0.000 & 0.045 \\
$\mathrm{Pt}$ & -7.727 & -0.800 & 0.212 & 0.520 \\
$\mathrm{~Pa}$ & -4.910 & -0.566 & 0.286 & 0.525 \\
\hline
\end{tabular}


Not: Bootstrap olasılık değerleri 200 adet bootstrap ile elde edilmiştir.

Tablo 7'de, Gt ve Ga istatistiklerinin bootstrap olasılık değerlerine göre, sıfır hipotezi \% 5 anlamlılık düzeyinde reddedilmiş, seriler arasında eşbütünleşme ilişkisinin varlı̆̆ anlaşılmıştır. 22 geçiş ekonomisinde vergi gelirleri ile finansal gelişmenin uzun dönemde birlikte hareket ettiği ifade edilebilir.

Seriler arasında eşbütünleşme ilişkisi tespit edildikten sonra uzun dönem eşbütünleşme katsayıları heterojenlik ve yatay kesit bağımlılığını dikkate alan CCE (Common Correlated Effect-Ortak Korelasyonlu Etkiler) yöntemi ile tahmin edilmiştir. Uzun dönem eşbütünleşme katsayılarının tahmininde CCEMG (Common Correlated Effects Mean Group-Ortak Korelasyonlu Etkiler Ortalama Grup) tahmincisi kullanılmıştır. CCEMG tahmin sonuçları Tablo 8'de gösterilmiştir.

Tablo 8. Uzun Dönem Eşbütünleşme Katsayıları

\begin{tabular}{lll}
\hline Ülkeler & \multicolumn{2}{c}{ FDI } \\
\cline { 2 - 3 } & Katsayı & Olasıllk \\
\hline Arnavutluk & 22.248 & 0.320 \\
Ermenistan & 23.012 & $0.000^{* * *}$ \\
Kazakistan & -8.597 & 0.899 \\
Moldova & 2.867 & 0.753 \\
Tacikistan & 65.105 & 0.409 \\
Ukrayna & 35.036 & 0.373 \\
Belarus & 74.973 & 0.143 \\
Bosna Hersek & 9.867 & 0.476 \\
Gürcistan & 10.405 & $0.000^{* * *}$ \\
Sirbistan & -27.602 & 0.341 \\
Bulgaristan & 47.368 & $0.034^{* *}$ \\
Hirvatistan & 18.687 & 0.169 \\
Çek Cumhuriyeti & 12.268 & 0.105 \\
Estonya & -28.950 & 0.167 \\
Macaristan & -0.563 & 0.914 \\
Letonya & -50.989 & $0.000^{* * *}$ \\
Litvanya & 16.071 & 0.156 \\
Polonya & 12.727 & 0.283 \\
Romanya & -10.039 & 0.390 \\
Slovakya & 94.113 & $0.000^{* * *}$ \\
Slovenya & 3.215 & $0.009^{* * *}$ \\
Rusya & 10.193 & 0.411 \\
Panel Geneli & 15.064 & $0.036^{* *}$ \\
\hline & & \\
\hline & 8.28 & \\
\hline
\end{tabular}


Not: ${ }^{* * *},{ }^{* *},{ }^{*}$ işaretleri \%1, \%5 ve \%10 düzeylerinde istatistiksel anlamlllı̆̆ göstermektedir.

Tablo 8 incelendiğinde, finansal gelişmedeki 1 birimlik artış vergi gelirlerini 15.064 birim artırmaktadır. Ülkeler boyutunda katsayılar Ermenistan, Gürcistan, Bulgaristan, Slovakya ve Slovenya'da finansal gelişmenin vergi gelirleri üzerinde pozitif ve anlamlı etkiye sahip olduğunu göstermektedir. Finansal gelişmenin vergi gelirleri üzerinde en fazla olumlu etkisinin olduğu ülkeler sirasıyla; Slovakya, Bulgaristan, Ermenistan, Gürcistan, Slovenya'dir.

Değişkenler arasında eşbütünleşme ilişkisinin olduğu anlaşıldıktan sonra değişkenler arasındaki nedensellik ilişkisinin olup olmadı̆̆ı, nedensellik ilişkisi var ise yönünü belirlemek amacıyla heterojen paneller için uygulanabilen Dumitrescu ve Hurlin panel nedensellik testine yer verilmiş, Tablo 9'da sunulmuştur.

Tablo 9. Dumitrescu ve Hurlin Panel Nedensellik Testi Sonuçları

\begin{tabular}{llll}
\hline Nedensellik Yönü & Z istatistiği & Olasılık & Karar \\
\hline FDI $\rightarrow$ TAX & 10.5524 & 0.0000 & Nedensellik Var \\
TAX $\rightarrow$ FDI & 9.0295 & 0.0000 & Nedensellik Var \\
\hline
\end{tabular}

Dumitrescu-Hurlin panel nedensellik test sonuçlarına göre, finansal gelişme ve vergi gelirleri arasında istatistiki açıdan anlamlı ve çift yönlü bir nedensellik ilişkisi mevcuttur. Bu ilişkinin tespit edilmesi, çalışmaya konu olan geçiş ekonomilerinde ilgili dönemde finansal gelişmenin vergi gelirlerini, vergi gelirlerinin de finansal gelişmeyi etkilediğini göstermektedir.

\section{Sonuç}

Finansal gelişme ve vergi gelirleri arasındaki ilişki son yıllarda yoğunlukla araştırılmaya başlanan bir konudur. 22 geçiş ekonomisinde finansal gelişmenin vergi gelirleri üzerindeki etkisini araştırmayı hedefleyen çalışmada, söz konusu ilişki 2004-2018 dönemi için ICTD ve IMF'den elde edilen veriler ile test edilmiştir. Bu kapsamda finansal gelişmeyi temsilen finansal gelişme endeksi, vergi gelirini temsilen vergi gelirlerinin GSYH içindeki \% payı kullanılmıştır. Değişkenler arasındaki ilişkilerin test edilebilmesi için sırasıyla homojenlik testi, yatay kesit bağımlılık testi, CADF panel birim kök testi, Westerlund panel eşbütünleşme testi, CCEMG tahmin yöntemi ve Dumitrescu ve Hurlin panel nedensellik testi kullanılmıştır.

Yatay kesit testi sonucuna göre, serilerde yatay kesit bağımlılığının olduğu, homojenlik testi sonucunda ise modelde heterojenliğin olduğu anlaşılmıştır. CADF panel birim kök testi sonucuna göre, finansal gelişme endeksi ve vergi gelirleri değişkenlerinin seviyelerinde durağan olmadıkları, ancak birinci farklarında durağan hale geldikleri tespit edilmiştir. Westerlund panel eşbütünleşme test sonuçlarına göre, finansal gelişme ve vergi gelirleri değişkenleri arasında uzun dönemde eşbütünleşme olduğu görülmüştür. CCEMG yöntemi ile eşbütünleşme katsayıları hem panelin bütünü hem de ülke bazında tahmin edilmiştir. Panelin bütününde yani geçiş ekonomilerinde finansal gelişmenin vergi gelirlerini pozitif ve anlamlı etkilediği sonucuna varılmıştır. Ancak ilişki ülke bazında incelendiğinde sadece Ermenistan, Gürcistan, Bulgaristan, Slovakya ve Slovenya'da finansal gelişmenin vergi gelirlerini pozitif etkilediği görülmektedir. Diğer taraftan bazı ülkelerde negatif katsayılar ve 
değişkenler arasındaki ilişkilerin ülkelerin kurumsal yapılarına ve makroekonomik koşullarına bağlı olarak değişebileceği söylenebilir. Dumitrescu ve Hurlin panel nedensellik testine göre ise, finansal gelişme ve vergi gelirleri arasında çift yönlü nedensellik ilişkisi olduğu ortaya çıkmıştır.

Çalışmada elde edilen bulgular, 22 geçiş ekonomisinde finansal gelişmenin vergi gelirlerini önemli bir derecede etkilediğini ortaya koymaktadır. Böylece elde edilen bulgular, literatür ile karşılaştırıldığında; finansal gelişmenin vergi gelirlerini pozitif etkilediği yönündeki Ilievski (2012), Taha ve diğerleri (2013), Akçay ve diğerleri (2016), Akram (2016) , Gilbert ve Ilievski (2016), Bayar ve Karamelikli (2017), Bayar ve diğerleri (2017), Ebi (2018), Nnyanzi ve diğerleri (2018), Gnangnon (2019), Pata ve Ela (2020), Topuz (2021) literatürleri ile örtüşmektedir. Bununla birlikte finansal gelişme ile vergi gelirleri arasındaki çift yönlü nedensellik ilişkisi bakımından Akram (2016), Pata ve Ela (2020) literatürünü desteklese de Taha ve diğerleri (2013), Akçay ve diğerleri (2016), Bayar ve diğerleri (2017) literatüründen ayrışmaktadır. Ayrıca literatürdeki Loganathan ve diğerleri (2017), Loganathan ve diğerleri (2020) çalışmalarında finansal gelişmenin vergi gelirlerini negatif etkilemesi, Taha ve diğerleri (2018) çalışmasının finansal gelişme ve vergi gelirleri arasında ters U ilişkisi olması bakımından da çalışmanın literatürden ayrıldığı görülmektedir. Belirtilmelidir ki, söz konusu literatürdeki benzerlik ve farklılıkların nedeni, çalışmalarda ele alınan ülkelerin kendine özgü özelliklerden kaynaklanabileceği ifade edilebilir.

Özetle, ülkelerin finansal gelişme yönünde ilerleme kaydetmesi, vergi mükelleflerinin kayıt dışı işlemlerini azaltabilir ve vergi gelirlerinin artmasını sağlayabilir. Bu bakımdan söz konusu geçiş ekonomilerinde politika yapıcıların finansal gelişmenin vergi mükelleflerini nasıl etkilediğini iyi analiz etmeleri gerektiği gibi bir önermede bulunulabilir. Bundan sonraki yapılacak çalışmalarda tek ülke ve daha uzun bir veri seti ile finansal gelişmenin vergi gelirleri üzerindeki etkisi analiz edilirse daha etkin sonuçlar elde edilebileceği söylenebilir.

\section{Kaynakça}

Akçay, S., Sağbaş, İ., \& Demirtaş, G. (2016). Financial development and tax revenue nexus in Turkey. Journal of Economics, 4(1), 103-108. DOI: 10.15640/jeds.v4n1a10

Akram, N. (2016). Do financial sector activities affect tax revenue in Pakistan?. The Lahore Journal of Economics, 21(2), 153-169. Erişim adresi: http://lahoreschoolofeconomics.edu.pk/EconomicsJournal/Journals/Volume\%2021/Issue\% 202/06\%20Akram.pdf

Bahtiyar, E., \& Odabaş, H. (2020). Vergi gelirlerini etkileyen bir faktör olarak ekonomik özgürlükler: OECD ülkeleri üzerinde bir analiz. Eskişehir Osmangazi Üniversitesi Sosyal Bilimler Dergisi, 21(1), 137-161. DOI: 10.17494/ogusbd.763561

Bayar, Y., \& Karamelikli, H. (2017). Financial development and tax revenues in Turkey: A non-linear cointegration analysis. The European Journal of Applied Economics, 14(2), 31-42. DOI: $10.5937 /$ ejae14-14838

Bayar, Y., Şaşmaz, M. Ü., \& Öztürk, Ö. F. (2017). Finansal gelişme ve vergi gelirleri: OECD ülkeleri örneği. Eurasian Academy of Sciences Eurasian Business \& Economics Journal, 12, 5163. DOI: http://dx.doi.org/10.17740/eas.econ.2017-V12-4 
Bittencourt, M., Gupta, R., \& Stander, L. (2014). Tax evasion, financial development and inflation: Theory and empirical evidence. Journal of Banking $\mathcal{E}$ Finance, 41, 194-208. DOI: http://dx.doi.org/10.1016/j.jbankfin.2014.01.009

Dumitrescu, E.I., \& Hurlin, C. (2012). Testing for granger non-causality in heterogeneous panels. Economic Modelling, 29(4), 1450-1460. Erişim adresi: https://halshs.archivesouvertes.fr/halshs-00224434/document

Ebi, B. O. (2018). Financial sector development and tax revenue in Nigeria. International Journal of Economics, Commerce and Management, 6(6), 93- 109. Erişim adresi: https://www.researchgate.net/profile/BasseyEbi/publication/326315128_Financial_Sector_ Development_and_Tax_Revenue_in_Nigeria/links/5b45692aaca272dc385f5d02/FinancialSector-Development-and-Tax-Revenue-in-Nigeria.pdf

Gilbert, S., \& Ilievski, B. (2016). Banks, development, and tax. The Quarterly Review of Economics and Finance, 1-39. DOI: http://dx.doi.org/doi:10.1016/j.qref.2016.01.001

Gnangnon, S. K. (2019). Financial development and tax revenuein developing countries: Investigating the international trade and economic growth channels. $Z B W-$ Leibniz Information Centre for Economics, 1-44. Erişim adresi: http://hdl.handle.net/10419/206628

ICTD (2021). https://www.ictd.ac/

IMF (2021). https://www.imf.org/

Ilievski, B. (2012). Tax revenue and financial development: Theory and evidence (Doctoral dissertation). Available from ProQuest Dissertations and Theses database (UMI No. 3514452).

Koç, S., Şenol, Z., \& Karaca, S. S. (2016). Analysis of developed and developing countries groups the macro-economic factors which are affected by finacial indicators: 2000-2012. Journal of Economics, Finance and Accounting, 3(4), 299-319. DOI: 10.17261/Pressacademia.2016.345

Loganathan, N., Ahmad, N., Subramaniam, T., \& Taha, R. (2020). The dynamic effects of growth, financial development and trade openness on tax revenue in Malaysia. International Journal of Business and Society, 21(1), 42-62. Erişim adresi: http://www.ijbs.unimas.my/images/repository/pdf/Vol21-no1-paper3.pdf

Loganathan, N., Ismail, S., Streimikiene D., Hassan, A. A. G., Zavadskas, E. K., \& Mardani, A. (2017). Tax reform, inflation, financial development and economic growth in Malaysia. Romanian Journal for Economic Forecasting, 20(4), 152-165. Erişim adresi: https://www.researchgate.net/profile/Abbas_Mardani2/publication/322330477_Tax_refor m_inflation_financial_development_and_economic_growth_in_Malaysia/links/5a56cc24ac a272bb6963f9f6/Tax-reform-inflation-financial-development-and-economic-growth-inMalaysia.pdf

Nnyanzi, J. B., Bbale, J. M., \& Sendi, R. (2018). Financial development and tax revenue: How catalytic are political development and corruption? International Journal of Economics and Finance, 10(8), 92-104. DOI: http s ://doi. 10.5539/ijef.v10n8p92

Pata, K., \& Ela, M. (2020). Türkiye'de finansal gelişmenin vergi gelirleri üzerindeki etkileri: Fourier eşbütünleşme ve nedensellik testleri. Mali Çözüm, 30(158), 171-188. Erişim adresi: https://www.researchgate.net/profile/MehmetEla/publication/340208911_TURKIYE\%27D 
E_FINANSAL_GELISMENIN_VERGI_GELIRLERI_UZERINDEKI_ETKILERI_FOURIER_ ESBUTUNLESME_VE_NEDENSELLIK_TESTLERI/links/5e7cf050a6fdcc139c08ba19/TUeR KIYEDE-FINANSAL-GELISMENIN-VERGI-GELIRLERI-UeZERINDEKI-ETKILERIFOURIER-ESBUeTUeNLESME-VE-NEDENSELLIK-TESTLERI.pdf

Pesaran M. H. (2007). A simple panel unit root test in the presence of cross-section dependence. Journal of Applied Econometrics, 22, 265-312. DOI: 10.1002/jae.951

Pesaran, M. H. (2006). Estimation and inference in large heterogeneous panels with a multifactor error structure. Econometrica, 74(4), 967-1012. Erişim adresi: http://hdl.handle.net/10419/18696

Pesaran, M. H. (2004). General diagnostic tests for cross section dependence in panels. Cambridge Working Papers in Economics, 435. Erişim adresi: http://hdl.handle.net/10419/18868

Pesaran, M. H., Ullah, A., \& Yamagata, T. (2008). A bias-adjusted LM test of error crosssection independence. The Econometrics Journal, 11(1), 105- 127. DOI: https://doi.org/10.1111/j.1368-423X.2007.00227.x

Pesaran, M. H., \& Yamagata, T. (2008). Testing slope homogeneity in large panels. Journal of Econometrics, 142(1), 50-93. DOI: https://doi.org/10.1016/j.jeconom.2007.05.010

Svirydzenka, K. (2016). Introducing a new broad-based index of financial development. IMF Working Paper, 1-42. Erişim adresi: https://www.imf.org/

Swamy, P.A.V.B. (1970). Efficient inference in a random coefficient regression model. Econometrica, 38(2), 311 323. Erişim adresi: http://links.jstor.org/sici?sici=00129682\%28197003\%2938\%3A2\%3C311\%3AEIIARC\%3E2.0.CO\%3B2-A

Taha, R., Sisira R.N. Colombage, S. M., \& Loganathan N. (2013). Does financial system activity affect tax revenue in Malaysia? Bounds testing and causality approach. Journal of Asian Economics, 24, 147-157. DOI: http://dx.doi.org/10.1016/j.asieco.2012.11.001

Taha, R., Šliogerienè, J., Loganathan, N., Jokšienè, I., Shahbaz, M., \& Mardani, A. (2018). The nexus between tax reformation, financial development and economic recovery: The case of Malaysia. Technological and Economic Development of Economy, 24(3), 1258-1279. DOI: https://doi.org/10.3846/tede.2018.1919

Tatoğlu, Yerdelen, F. (2017). Panel Zaman Serileri Analizi. İstanbul: Beta Basım.

Terefe, K. D., \& Teera, J. (2018). Determinants of tax revenue in East African countries: An application of multivariate panel data cointegration analysis. Journal of Economics and International Finance, 10(11), 134-155. DOI: 10.5897/JEIF2018.0924

Tzougas, J. (2013). Tax revenue, private investment and real income in Greece: Evidence from multivariate cointegration and causality analysis. Erişim Adresi: https://papers.ssrn.com/sol3/papers.cfm?abstract_id=2296000

Topuz, S. H. (2021). Gelişmekte olan ülkelerde finansal gelişmenin vergi gelirleri üzerindeki etkisi. Balkan and Near Eastern Journal of Social Sciences, 7(1), 7-15. Erişim adresi: http://www.ibaness.org/bnejss/2021_07_01/02_Topuz.pdf

Westerlund, J. (2007). Testing for error correction in panel data. Oxford Bulletin of Economics and Statistics, 69, 709-748. DOI: https://doi.org/10.1111/j.1468-0084.2007.00477.x 